\title{
PENGARUH LEVERAGE DAN FREE CASH FLOW TERHADAP KEBIJAKAN DIVIDEN PADA PERUSAHAAN INDEKS LQ45 YANG TERDAFTAR DI BURSA EFEK INDONESIA TAHUN (2012-2016)
}

\author{
Siska Mangundap ${ }^{1}$, Ventje Ilat ${ }^{2}$, Rudy Pusung $^{3}$ \\ 1,2,3 Jurusan Akuntansi, Fakultas Ekonomi dan Bisnis, Universitas Sam Ratulangi, Jl. Kampus Bahu, Manado, \\ 95115, Indonesia \\ E-mail : siskamangundap24@yahoo.co.id
}

\begin{abstract}
This study aims to determine the effect of leverage and free cash flow on dividend policy on LQ45 index companies listed in Indonesia Stock Exchange 2012-2016. The population used in this study is the LQ45 index company listed on the Indonesia Stock Exchange 2012-2016. Method of sampling by purposive sampling according to predetermined criteria. The number of samples collected were 11 companies. Research data is secondary data obtained from Indonesia stock exchange (IDX) year 2012-2016. The collected data is analyzed by using data analysis which is done by classical assumption test before doing hypothesis testing. Hypothesis testing in this study using multiple linear regression analysis with t test, f test, and coefficient of determination. The results of this study indicate that leverage variables have a negative and significant effect on dividend policy. This suggests that leverage can affect the high dividend policy. While free cash flow has a positive and insignificant effect on dividend policy. This shows that free cash flow does not affect the high dividend policy.
\end{abstract}

Keywords: leverage, free cash flow, dividend

\section{PENDAHULUAN}

Era globalisasi yang semakin pesat serta adanya suatu dorongan integrasi ekonomi melalui masyarakat ekonomi (MEA) ini meningkatkan gairah pengusaha-pengusaha baru untuk mendirikan suatu perusahaan dengan meningkatkan kinerja perusahaannya agar mampu bertahan dan tetap eksis dan ikut bersaing dalam pasar global. Kebutuhan akan dana sangat penting bagi setiap perusahaan karena setiap kegiatan perusahaan membutuhkan dana. Pasar modal dalam teori Fahmi (2015:48) merupakan tempat dimana berbagai pihak khususnya perusahaan menjual saham dan obligasi dengan tujuan hasil penjualan tersebut nantinya dipergunakan sebagai tambahan dana atau untuk memperkuat modal perusahaan Fahmi (2015:48). Tujuan perusahaan adalah untuk memaksimumkan laba dari suatu perusahaan. Namun seiring dengan berkembangnya ilmu keuangan yang begitu pesat, tujuan dari suatu perusahaan harus mampu menciptakan nilai bagi pemiliknya. Hal ini dilakukan melalui pemberian dividen. Ary (2013:226) Dividen adalah bagian dari keuntungan yang dibagikan kepada pemegang saham yang dapat berupa dividen tunai atau dividen saham. Pemberian dividen suatu perusahaan melibatkan kedua belah pihak yang mempunyai kepentingan dan saling bertolak belakang, besar kecilnya dividen yang akan dibayarkan oleh perusahaan tergantung pada kebijakan dividen dari setiap perusahaan. Leverage yang diukur dengan debt to equity ratio adalah rasio yang menunjukkan perbandingan antara utang dan equitas perusahaan. Semakin besar rasio ini maka semakin besar penggunaan utang suatu perusahaan dan akan mengakibatkan semakin sulit perusahaan untuk membayar dividen. Pemberian dividen suatu perusahaan juga dapat dipengaruhi oleh free cash flow yang merupakan aliran arus kas yang menggambarkan tentang keuangan perusahaan. Free cash flow sangat berguna bagi perusahaan, free cash flow yang besar menunjukkan bahwa 
perusahaan dapat melakukan pengembalian modal baik dalam bentuk utang maupun ekuitas. Free cash flow perusahaan yang besar maka dividen yang dibayarkan juga besar. LQ45 yaitu indeks pasar saham Bursa Efek Indonesia (BEI) yang terdiri dari perusahaan yang memiliki tingkat likuiditas dan kapitalisasi pasar yang tinggi. Hal ini menjadi pertimbangan bahwa perusahaan indeks LQ45 merupakan 45 perusahaan teratas sehinggan kemungkinan investor akan memilih perusahaan yang melakukan pembagian dividen yang stabil.

\section{TINJAUAN PUSTAKA}

\subsection{Akuntansi Keuangan}

Akuntansi keuangan mempunyai hubungan yang erat dengan pihak eksternal dengan mempunyai tujuan yang spesifik dengan masing-masing pihak penyusun laporan keuangan dengan menggunakan prinsip dan asumsi-asumsi. Sehingga, diperlukan standar akuntansi yang dijadikan pedoman baik oleh penyusun maupun oleh pembaca laporan keuangan

\subsection{Laporan Keuangan}

Dalam Pernyataan Standar Akuntansi Keuangan (PSAK) Laporan Keuangan yaitu laporan keuangan yang menyediakan informasi menyangkut posisi keuangan, kinerja, serta perubahan posisi keuangan perusahaan yang ditujukan untuk memenuhi kebutuhan bersama sebagaian besar pengguna laporan (IAI,2013).

\subsection{Pasar Modal}

Bertanggungjawab dalam sektor perekonomian negara karena pasar modal menjalankan dua fungsi, yaitu sebagai suatu sarana bagi pendanaan usaha atau sarana bagi perusahaan untuk mendapatkan dana dari pihak yang menanamkan modal dan menjadi pihak yang memfasilitasi kegiatan investasi pada instrument keuangan yang dilakukan oleh masyarakat seperti saham, obligasi, dan lain-lain.

\subsection{Agency Theory}

Teori keagenan menyatakan bahwa principal adalah pemegang saham sedangkan agen adalah para manajemen (CEO), yang dipercaya oleh principal untuk mengelola perusahaan, dan dalam menjalankan usaha biasanya pemilik menyerahkan kepada manajer sehingga menyebabkan timbulnya hubungan keagenan.

\subsection{Dividen}

Dalam teori Nikforos (2013:300) menyatakan bahwa dividen merupakan pembayaran tunai yang dibayarkan oleh perseroan kepada pemegang saham. Tinggi rendahnya jumlah suatu dividen yang dibayarkan kepada pemegang saham tergantung dari kebijakan dividen dari setiap perusahaan yang ditentukan dalam rapat Umum Pemegang Saham (RUPS). Tujuan pembagian dividen adalah untuk memaksimumkan kemakmuran bagi para pemegang saham, untuk menunjukkan likuiditas perusahaan, risiko dividen lebih rendah dibanding capital gain, memenuhi kebutuhan para pemegang saham, dan digunakan sebagai alat komunikasi antara manajer dan pemegang saham.

\subsubsection{Kebijakan Dividen}

Kebijakan pembayaran dividen oleh perusahaan, berupa penentuan besarnya pembayaran dan besarnya laba yang ditahan untuk kepentingan suatu perusahaan jika memilih untuk membagikan laba dalam bentuk dividen, maka akan mengurangi laba yang ditahan dan selanjutnya mengurangi total sumber dana. Kemudiaan jika suatu perusahaan memilih untuk menahan laba yang diperoleh, maka kemampuan pembentukan dana intern akan semakin besar.

\subsection{Leverage}

Leverage merupakan pemakaian asset atau aktiva tetap dan sumber dana di mana untuk penggunaan aktiva tetap dan dana pinjaman tersebut perusahaan harus mengeluarkan biaya tetap dan beban bunga. Kesanggupan perusahaan untuk memakai aktiva atau dana untuk memperbesar tingkat penghasilan bagi pemilik perusahaan dengan memperbesar 
tingkat leverage maka hal ini akan berarti bahwa tingkat ketidakpastian dari return yang akan didapat akan menjadi tinggi, tetapi pada saat yang sama hal tersebut akan memperbesar jumlah return yang akan diperoleh. Tingkat leverage dalam perusahaan bisa saja berbedabeda, tetapi yang jelas, semkin tinggi leverage akan semakin tinggi risiko yang dihadapi serta semakin besar penghasilan yang diharapkan.

\subsection{Free Cash Flow}

Setelah perusahaan menempatkan seluruh investasinya pada aktiva tetap, produkproduk baru dan modal kerja yang dibutuhkan untuk mempertahankan operasi yang sedang berjalan, sementara arus kas bebas yang tersisa dibagikan kepada seluruh pemegang saham dan pemilik hutang (Toto, 2012:220). Arus kas bebas (Free Cash Flow) dapat dihitung dengan menggunakan rumus:

\section{Free Cash Flow $(\mathrm{FCF})=$ Arus Kas Operasi - Belanja Modal}

\subsection{Penelitian terdahulu}

1. Penelitian yang dilakukan oleh Sista (2015), menyatakan bahwa leverage berpengaruh signifikan terhadap kebijakan dividen

2. Penelitian yang dilakukan oleh Rizky (2016), menyatakan bahwa free cash flow berpengaruh signifikan terhadap kebijakan dividen

\subsection{Hipotesis}

$\mathrm{H} 1$ = leverage berpengaruh signifikan terhadap kebijakan dividen

$\mathrm{H} 2$ = free cash flow berpengaruh signifikan terhadap kebijakan dividen

\section{METODE PENELITIAN \\ 3.1 Jenis Penelitian}

Jenis penelitian yang digunakan dalam penelitian ini adalah metode penelitian kuantitatif asosiatif, penelitian asosiatif adalah penelitian yang bertujuan untuk mengetahui pengaruh ataupun juga hubungan antar dua variabel atau lebih (Sugiyono 2013:11). Dalam penelitian ini, metode asosiatif digunakan untuk mengetahui pengaruh leverage dan free cash flow terhadap kebijakan dividen pada perusahaan indeks LQ45 yang terdaftar di Bursa Efek Indonesia.

\subsection{Tempat dan Waktu Penelitian}

Penelitian ini dilakukan di beberapa perusahaan indeks LQ45 yang terdaftar di Bursa Efek Indonesia (BEI). Berdasarkan data yang diperoleh melalui situs BEI di www.idx.co.id dan di pusat informasi pasar modal yang terletak di Jl. Piere Tendean Kompelks Mega Mas Boulevard Manado, penelitian ini dilaksanakan pada tahun 2018 dan diperkirakan dilakukan selama 2 bulan.

\subsection{Populasi dan Sampel}

Populasi dari penelitian ini adalah seluruh perusahaan indeks LQ45 yang terdaftar di Bursa Efek Indonesia. Sampel yang dipakai dalam penelitian ini menggunakan metode purposive sampling, yang mana pemilihan sampel secara tidak acak yang informasinya diperoleh dengan menggunakan pertimbangan tertentu. Perusahaan diseleksi berdasarkan kriteria-kriteria sebagai berikut:

1.Perusahaan indeks LQ45 yang terdaftar di Bursa Efek Indonesia selama tahun 2012-2016

2.Perusahaan indeks LQ45 tersebut menerbitkan laporan keuangan berakhir 31 desember dan sudah diaudit dengan kriteria mendapatkan laba tahun 2012-2016

3.Perusahaan tersebut menggunakan mata uang rupiah selama tahun 2012-2016

4.Perusahaan tersebut membagikan dividen secara terus-menerus dari tahun 2012-2016 


\subsection{Jenis dan Sumber Data}

\subsubsection{Jenis Data}

Jenis data dalam penelitian ini menggunakan data kuantitatif, yaitu data yang mengandung angka atau bilangan yang digunakan dalam menjelaskan berbagai gambaran dan peristiwa sehubungan dengan pelaksanaan penelitian. Data berbentuk angka diperoleh dari laporan keuangan yang telah diaudit.

\subsubsection{Sumber Data}

Sumber data dalam penelitian ini adalah data sekunder yang diperoleh dalam bentuk dokumentasi laporan keuangan yang rutin diterbitkan setiap tahun oleh perusahaan dari situs resmi Bursa Efek Indonesia (www.idx.co.id).

\subsection{Definisi Operasional Variabel}

\subsubsection{Variabel Dependen}

Variabel dependen dalam penelitian ini adalah kebijakan dividen. Kebijakan dividen merupakan keputusan untuk menentukan besarnya bagian pendapatan yang akan dibagikan kepada para pemegang saham dan bagian yang akan ditahan diperusahaan (Wicaksono dan Nasir, 2014). Variabel ini di ukur dengan dividend payout ratio.

$$
\text { Dividend Payout Ratio }=\frac{\text { Dividend per share }}{\text { Earning per share }}
$$

\subsubsection{Variabel Independen}

Variabel independen dalam penelitian ini adalah:

\section{Leverage}

Leverage merupakan rasio yang menggambarkan hubungan antara utang perusahaan terhadap modal, Semakin besar rasio leverage, berarti semakin tinggi utang perusahaan. Variabel leverage di ukur dengan rasio total debt-to-equity.

$$
\text { Total Debt to Equity }=\frac{\text { Total Liabilities }}{\text { Total Shareholders Equity }}
$$

\section{Arus Kas Bebas ( Free Cash Flow)}

Free Cash Flow seperti namanya, arus kas bebas, artinya arus kas yang tersisa setelah perusahaan membayar beban-beban operasional dan kebutuhan investasinya. Variabel arus kas bebas di ukur sebagai berikut

\section{Arus Kas Bebas = Arus Kas dari Operasi - Belanja Modal}

\subsection{Teknik Pengumpulan Data}

Teknik pengumpulan data menggunakan teknik dokumentasi, yaitu dengan melihat dokumen yang sudah terjadi (laporan keuangan) di Bursa Efek Indonesia. Dalam penelitian ini data diperoleh dari akses website Bursa Efek Indonesia (www.idx.co.id). Penelitian juga menggunakan studi kepustakaan yaitu dengan cara membaca,mempelajari literatur dan publikasi yang berhubungan dengan penelitian.

\subsection{Teknik Analisis Data}

\subsubsection{Uji Asumsi Klasik}

Pengujian regresi dapat dilakukan setelah model dari penelitian ini memenuhi syarat uji asumsi klasik. Dengan adanya pengujian ini diharapkan agar model regresi yang diperoleh dapat dipertanggungjawabkan. Oleh karena itu, perlu dilakukan uji asumsi klasik sebelum melakukan uji regresi dan uji hipotesis yang terdiri dari: 
1. Uji Normalitas, yang bertujuan apakah dalam model regresi, variabel independen dan dependen berdistribusi normal atau tidak.

2. Uji Multikolinieritas, yang bertujuan apakah pada model regresi ditemukan adanya korelasi antar variabel independen.

3. Uji Heteroskedastisitas, menguji apakah dalam regresi terjadi ketidaksamaan variance dari residual suatu pengamatan ke pengamatan yang lain.

\subsubsection{Uji Regresi Linear Berganda}

Model regresi yang digunakan dapat dirumuskan dengan persamaan sebagai berikut: $\mathrm{Y}=\mathrm{a}+\mathrm{b} 1 \mathrm{X} 1+\mathrm{b} 2 \mathrm{X} 2+e$

Keterangan:

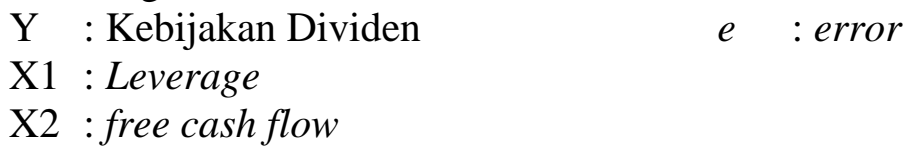

\subsubsection{Koefisien Determinasi $\left(\mathbf{R}^{2}\right)$}

Untuk menilai berapa jauh kesanggupan model dalam menerangkan variabelvariabel dependen merupakan definisi menurut Ghozali (2013:97). Nilai koefisien determinasi adalah antara nol dan satu.

\subsubsection{Uji Hipotesis}

1. Uji t (Uji Parsial)

Uji t digunakan untuk menguji hipotesis secara parsial dari variabel bebasnya. Pengujian ini dilakukan dengan cara membandingkan t-hitung dengan t-tabel. Jika t-hitung lebih besar dibandingkan dengan t-tabel pada taraf signifikansi $(\alpha) 5 \%$, maka variabel pengaruh memiliki pengaruh yang signifikan.

2. Uji f (Uji Simultan)

Uji t digunakan untuk menguji hipotesis secara simultan. Pengujian ini dilakukan dengan cara membandingkan f-hitung dengan f-tabel. Jika f-hitung lebih besar dibandingkan dengan f-tabel pada taraf signifikansi $(\alpha) 5 \%$, maka variabel pengaruh memiliki pengaruh yang signifikan.

\section{HASIL ANALISIS DAN PEMBAHASAN}

\subsection{Hasil analisis}

\subsubsection{Uji Asumsi Klasik}

Uji Normalitas

Dari Hasil uji normalitas diperoleh hasil sebagai berikut.

Tabel 4.2 Uji Normalitas Kolmogorov - Smirnov One-Sample Kolmogorov-Smirnov Test

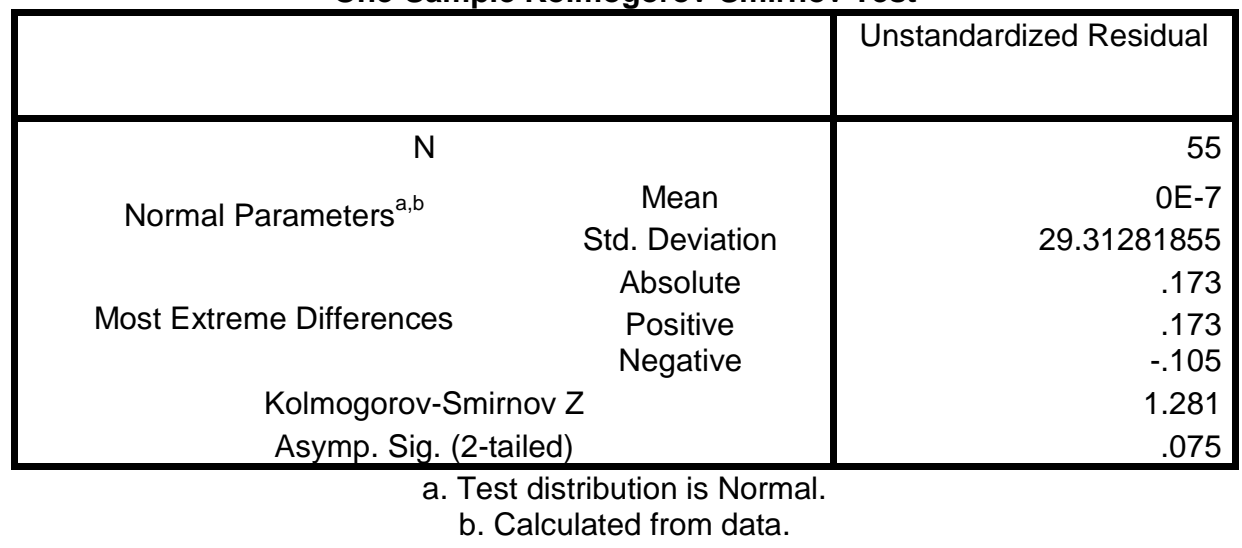

(Sumber : Hasil Pegolahan Data Aplikasi SPSS, 2018) 
Berdasarkan hasil uji normalitas kolmogorov - Smirnov diperoleh nilai signifikansi sebesar 0,075 (Asymp. Sig. (2-tailed)) dimana 0,075 > 0,05 maka dapat disimpulkan bahwa data berdistribusi normal.

Uji Multikolinearitas

Dari hasil uji multikolinearias diperoleh hasil untuk masing-masing variabel sebagai berikut.

Tabel 4.3 Uji Multikolinearitas

\begin{tabular}{|c|c|c|}
\hline \multirow[t]{2}{*}{ Model } & \multicolumn{2}{|c|}{ Collinearity Statistics } \\
\hline & Tolerance & VIF \\
\hline (Constant) & & \\
\hline Leverage & .983 & 1.017 \\
\hline FCF & .983 & 1.017 \\
\hline
\end{tabular}

a. Dependent Variable: Kebijakan Dividen

(Sumber : Hasil Pegolahan Data Aplikasi SPSS, 2018)

Berdasarkan hasil uji multikolinearitas diperoleh Leverage nilai tolerance 0,983 > 0,1 dan nilai VIF 1,017 < 10, Free Cash Flow (FCF) nilai tolerance 0,983 > 0,1 dan nilai VIF 1,017 $<10$, Jadi dapat disimpukan bahwa tidak ada multikolinearitas antara variabel independen dalam model regresi karena semua variabel independen memiliki nilai tolerance $>0,1$ dan nilai VIF $<10$.

Uji Heteroskedastisitas

Dari hasil uji heteroskedastisitas diperoleh hasil sebagai berikut.

Tabel 4.4 Uji Glejser

\begin{tabular}{|c|c|}
\hline Model & Sig. \\
\hline (Constant) & .005 \\
Leverage & .074 \\
FCF & .389 \\
\hline
\end{tabular}

a. Dependent Variable: Kebijakan Dividen RES2

(Sumber : Hasil Pegolahan Data Aplikasi SPSS, 2018)

Berdasarkan hasil uji glesjer diperoleh Leverage nilai signifikansi 0,074 > 0,05, Free Cash Flow (FCF) nilai signifikansi 0,389 > 0,05. Jadi dapat disimpukan bahwa tidak terjadi heteroskedastisitas pada model regresi karena signifikansi (sig.) semua variabel independen > 0,05 .

\subsubsection{Uji Regresi Linear Berganda}

Hasil uji regresi linear berganda diperoleh hasil sebagai berikut.

Tabel 4.5 Uji Regresi Linear Berganda Coefficients $^{\mathbf{a}}$

\begin{tabular}{|c|c|c|c|c|c|c|}
\hline \multirow{2}{*}{\multicolumn{2}{|c|}{ Model }} & \multicolumn{2}{|c|}{ Unstandardized Coefficients } & Standardized & \multirow[t]{2}{*}{$\mathrm{T}$} & \multirow[t]{2}{*}{ Sig. } \\
\hline & & $\mathrm{B}$ & Std. Error & Beta & & \\
\hline \multirow{3}{*}{1} & (Constant) & 66.019 & 15.959 & & 4.137 & .000 \\
\hline & Leverage & -6.279 & 1.927 & -.415 & -3.259 & .002 \\
\hline & FCF & .035 & .878 & .005 & .039 & .969 \\
\hline
\end{tabular}

a. Dependent Variable: Kebijakan Dividen

(Sumber : Hasil Pegolahan Data Aplikasi SPSS, 2018)

Dari Tabel 4.6 dapat diperoleh persamaan regresi linier berganda sebagai berikut. $\mathrm{Y}=66,019+(-6,279) \mathrm{X} 1+0,035 \mathrm{X} 2+\mathrm{e}$

Keterangan: 


\section{Y : Kebijakan Dividen \\ $\mathrm{X} 1$ : Leverage \\ $\mathrm{X} 2$ : Free Cash Flow \\ e : Standart error}

\subsubsection{Koefisien Determinasi $\left(\mathbf{R}^{2}\right)$}

Dari hasil uji regresi linear berganda diperoleh hasil sebagai berikut :

\section{Tabel 4.6 Koefisien Determinasi} Model Summary ${ }^{\circ}$

\begin{tabular}{|c|r|r|r|c|}
\hline Model & $\mathrm{R}$ & $\mathrm{R}$ Square & \multicolumn{1}{c|}{$\begin{array}{c}\text { Adjusted } \mathrm{R} \\
\text { Square }\end{array}$} & $\begin{array}{c}\text { Std. Error of the } \\
\text { Estimate }\end{array}$ \\
\hline 1 & $.415^{\mathrm{a}}$ & .173 & .141 & 29.87121 \\
\hline
\end{tabular}

a. Predictors: (Constant), FCF, Leverage

b. Dependent Variable: Kebijakan Dividen

(Sumber : Hasil Pegolahan DataAplikasi SPSS, 2018)

Dari hasil pengolahan data dengan metode regresi linear berganda, diperoleh hasil koefisien determinasi berdasarkan nilai adjusted yaitu sebesar 0,141. Jadi kemampuan variabel independen yaitu leverage dan free cash flow dari variabel dependen yaitu kebijakan dividen sebesar $14,1 \%$ sedangkan sisanya sebesar $85,9 \%$ dijelaskan oleh faktor-faktor lain yang tidak diikut sertakan dalam penelitian ini.

\subsubsection{Uji Hipotesis}

Uji t (Uji Parsial)

Dari hasil uji regresi linear berganda diperoleh hasil sebagai berikut.

\section{Tabel 4.7 Uji t}

Coefficients $^{\mathrm{a}}$

\begin{tabular}{|c|c|c|c|c|c|c|}
\hline & \multirow[t]{2}{*}{ Model } & \multicolumn{2}{|c|}{ Unstandardized Coefficients } & \multirow{2}{*}{$\begin{array}{c}\text { Standardized } \\
\text { Coefficients } \\
\text { Beta }\end{array}$} & \multirow[t]{2}{*}{$\mathrm{T}$} & \multirow[t]{2}{*}{ Sig. } \\
\hline & & $B$ & Std. Error & & & \\
\hline \multirow{3}{*}{1} & (Constant) & 66.019 & 15.959 & & 4.137 & .000 \\
\hline & Leverage & -6.279 & 1.927 & -.415 & -3.259 & .002 \\
\hline & FCF & .035 & .878 & .005 & .039 & .969 \\
\hline
\end{tabular}

a. Dependent Variable: Kebijakan Dividen

(Sumber : Hasil Pegolahan Data Aplikasi SPSS, 2018)

Berdasarkan hasil analisis regresi secara parsial, maka diperoleh leverage memiliki nilai thitung sebesar 3,259 > 2,005 dan nilai signifikansi 0,002 <0,05, free cash flow memiliki nilai t-hitung sebesar $0,039<2,005$ dan nilai signifikansi 0,969 > 0,05. Jadi dapat disimpulkan bahwa leverage berpengaruh signifikan terhadap kebijakan dividen maka $\mathrm{H} 1$ diterima karena t-hitung > t-tabel dan tingkat signifikansi $<0,05$, dan free cash flow tidak berpengaruh signifikan terhadap kebijakan dividen maka $\mathrm{H} 2$ ditolak karena t-hitung < t-tabel dan tingkat signifikansi $>0,05$.

Uji F (Simultan)

Dari hasil uji regresi linear berganda diperoleh hasil sebagai berikut : 
Tabel 4.8 Uji F

ANOVA $^{\mathrm{a}}$

\begin{tabular}{|c|c|c|c|c|c|c|}
\hline & Model & Sum of Squares & $\mathrm{Df}$ & Mean Square & $\mathrm{F}$ & Sig. \\
\hline \multirow{3}{*}{1} & Regression & 9674.105 & $\overline{2}$ & 4837.052 & 5.421 & $.007^{b}$ \\
\hline & Residual & 46399.032 & 52 & 892.289 & & \\
\hline & Total & 56073.137 & 54 & & & \\
\hline
\end{tabular}

a. Dependent Variable: KD

b. Predictors: (Constant), FCF, Leverage

(Sumber : Hasil Pegolahan Data Aplikasi SPSS, 2018)

Berdasarkan hasil analisis regresi uji f, maka diperoleh nilai F-hitung sebesar 5,421 > 3,160 dan nilai signifikansi 0,007 <0,05. Jadi dapat disimpulkan bahwa leverage dan free cash flow berpengaruh signifikan terhadap kebijakan dividen.

\subsection{Pembahasan}

a. Pengaruh Leverage terhadap Kebijakan Dividen

Berdasarkan hasil pengujian yang dilakukan diketahui bahwa leverage berpengaruh signifikan terhadap kebijakan dividen. Dengan demikian H1 diterima sesuai dengan hasil uji hipotesis parsial (uji t). leverage mempunyai hubungan berlawanan arah atau negatif terhadap kebijakan dividen, dimana semakin besar leverage maka pembagian dividen semakin berkurang. Hasil penelitian ini dikhususkan pada objek penelitian perusahaan indeks LQ45 yang terdaftar di Bursa Efek Indonesia periode 2012 sampai dengan 2016.

b. Pengaruh Free Cash Flow terhadap Kebijakan Dividen

Berdasarkan hasil pengujian yang dilakukan diketahui bahwa free cash flow tidak berpengaruh signifikan terhadap kebijakan dividen. Dengan demikian H2 ditolak sesuai dengan hasil uji hipotesis parsial (uji t). free cash flow mempunyai hubungan searah atau positif terhadap kebijakan dividen, dimana semakin besar free cash flow maka kebijakan dividen semakin bertambah. Hasil penelitian ini dikhususkan pada objek penelitian perusahaan indeks LQ45 yang terdaftar di Bursa Efek Indonesia periode 2012 sampai dengan 2016.

\section{KESIMPULAN DAN SARAN}

\subsection{Kesimpulan}

Berdasarkan hasil penelitian yang telah dikemukakan di atas, maka dapat ditarik kesimpulan sebagai berikut:

1. Leverage berpengaruh negatif dan signifikan terhadap kebijakan dividen, terbukti dengan hasil uji hipotesis parsial (uji t) yang telah di lakukan yang memiliki nilai t-hitung sebesar $3,259>2,005$ dan nilai signifikansi 0,002 <0,05. Jadi dapat disimpulkan bahwa leverage berpengaruh signifikan terhadap kebijakan dividen maka $\mathrm{H} 1$ diterima karena t-hitung $>\mathrm{t}$ tabel dan tingkat signifikansi $<0,05$.

2. Free cash flow berpengaruh positif dan tidak signifikan terhadap kebijakan dividen, terbukti dengan hasil uji hipotesis parsial (uji t) yang telah di lakukan yang memiliki nilai t-hitung sebesar $0,039<2,005$ dan nilai signifikansi 0,969 > 0,05. Jadi dapat disimpulkan free cash flow tidak berpengaruh signifikan terhadap kebijakan dividen maka $\mathrm{H} 2$ ditolak karena t-hitung $<$ t-tabel dan tingkat signifikansi $>0,05$.

\subsection{Saran}

Berdasarkan hasil penelitian yang telah dikemukakan di atas, maka penulis memberikan saran yang mungkin dapat digunakan sebagai dasar pertimbangan bagi perusahaan dan pihak-pihak lain yang berkepentingan, dan saran yang diberikan yaitu sebagai berikut:

1. Bagi perusahaan, pada penelitian leverage berpengaruh signifikan terhadap kebijakan dividen. Hal ini menunjukkan bahwa manajemen perlu memperhatikan faktor tersebut sehingga dapat menunjang tingkat pembagian dividen dan perusahaan juga dapat melihat 
free cash flow sebagai salah satu indikator yang dapat digunakan perusahaan untuk meningkatkan pembagian dividen

2. Bagi investor, untuk menanamkan modalnya ke perusahaan dan menginginkan pembagian dividen yang jumlahnya relatif besar sebaiknya melihat laba yang dihasilkan oleh perusahaan. Agar investor dapat memilih perusahaan mana yang akan dipilih untuk berinvestasi.

3. Bagi Peneliti Selanjutnya

a. Tahun observasi sebaiknya diperpanjang karena dengan perpanjangan periode akan lebih terlihat knsistensi pengaruh variabel-variabel bebas tersebut terhadap kebijakan dividen.

b. Peneliti selanjutnya lebih baik melakukan penelitian lebih lanjut lagi mengenai factorfaktor yang mempengaruhi kebijakan dividen ini. Penelitian selanjutnya sebaiknya tidak hanya menggunakan variabel yang sudah digunakan dalam penelitian ini tetapi bisa memperbanyak indikator lainnya yang dapat mempengaruhi kebijakan dividen, yakni likuiditas, ukuran perusahaan, management ownership, peluang investasi, struktur kepemilikan saham dan sebagainya.

\section{DAFTAR PUSTAKA}

Gumanti, Ary. 2013. Kebijakan Dividen Teori, Empiris, dan Implikasi. Jakarta: UPP STIM YKPN.

Fahmi, Irham. 2015. Manajemen Investasi. Jakarta: Salemba Empat.

Ghozali, Imam. 2013. Aplikasi Analisis Multivariate dengan Program IBM SPSS 21 Update PLS Regresi. Semarang: Badan Penerbit Universitas Diponegoro.

Ikatan Akuntan Indonesia. 2015. Standar Akuntansi Keuangan Nomor 107 tentang Akuntansi Ijarah. Jakarta: Ikatan Akuntansi Indonesia

Laopodis, Nikforos K. 2013. Understanding Investments: Theories and Strategies. New York: Routledge

Paramita. R.A. Sista. 2015. Pengaruh Free Cash Flow, Leverage, Besaran dan Siklus Hidup Terhadap Kebijakan Dividen di BEI Tahun 2011-2013. Jurnal Riset Ekonomi dan Manajemen: Volume 15 Nomor 1 Universitas Negeri Surabaya.

Pribadi, Toto. 2012. Memahami Laporan Keuangan Sesuai IFRS dan PSAK. Jakarta: PPM Manajemen.

Suci. I. W. Rizky. 2016. Pengaruh arus kas bebas, kebijakan pendanaan, profitabilitas, collateral asset terhadap kebijakan dividen di BEI 2011-2014. Jurnal Ilmu dan Riset Akuntansi: Volume 5 Nomor 2 Sekolah Tinggi Ilmu Ekonomi Indonesia Surabaya.

Sugiyono. 2013. Metode Penelitian Kuantitatif, Kualitatif dan R\&D. Bandung: PT Alfabet. 